Running head: The social construction of conspiracy beliefs

The social construction of conspiracy beliefs:

A Q-methodology study of how ordinary people define them and judge their plausibility

Lauren Daniel \& David J. Harper

Mental Health \& Social Change Research Group

School of Psychology

University of East London

London E15 4LZ

United Kingdom

Correspondence concerning this article should be addressed to Professor David Harper: Mental Health \& Social Change Research Group, School of Psychology, University of East London, London E15 4LZ, UK. E-mail: d.harper@uel.ac.uk 
Running head: The social construction of conspiracy beliefs

\begin{abstract}
Little is known about ordinary people's understandings of conspiracy beliefs and how these understandings relate to the perspectives of researchers and scholars. Working within a social constructionist epistemological framework, we conducted a Q-methodology study aiming to identify a range of lay perspectives on two key topics: the defining features of conspiracy beliefs; and aspects considered important in judging their plausibility. Fifty-six people (32 men and 24 women), recruited via regional UK Facebook groups, sorted their agreement with a set of statements on each of the two topics. A principal component analysis, followed by varimax rotation, was performed on each data set. Five accounts about the defining features of conspiracy beliefs were identified: that they are false, illogical and harmful; that they are forms of political critique; that there are varied types; that they are entertaining but ineffectual; and that they are held by a self-reinforcing minority. Four accounts about their evaluation were identified: conventional realist criteria; the importance of personal judgement; skeptical realism; and the assessment of critical thinking. The findings are discussed in the context of the literature and limitations of the study are considered. Implications for research and educational and policy interventions are outlined.
\end{abstract}

Keywords: Conspiracy belief; Conspiracy theories; Q-methodology; plausibility judgements; heuristics; social construction 


\section{The social construction of conspiracy beliefs: A Q-methodology study of how ordinary people define them and judge their plausibility}

\section{Introduction}

It is hard to think of any contemporary area of politics or public policy, internationally, where conspiracy beliefs are not currently a matter of debate in public discourse. But how we conceive of them shapes both our research strategy and policy interventions. For example, are we living in a "golden age of conspiracy theories" (Guilhot \& Moyn, 2020) or have they been even more prevalent historically (Uscinski \& Parent, 2014)? Are they inherently harmful or are some harmless and even entertaining?

Conspiratorial beliefs have received increased attention from both journalists and researchers in recent years (Butter \& Knight, 2019) but they are often discussed as if they were understood to have a stable and universal definition and to be self-evidently implausible. Yet, surprisingly, there has been little investigation of whether lay people share these assumptions. Without such an understanding, there is a risk that public discussion about conspiracy beliefs and interventions to counter those with harmful consequences are misdirected and, potentially, counterproductive. Since the general population is comprised of different groups and sub-cultures, the extent to which researcher definitions of conspiratorial belief are shared by ordinary people might vary.

The conceptual and methodological assumptions of researchers can have a significant influence on how conspiracy beliefs are understood. For example, a recent survey of Coronavirus conspiracy beliefs amongst 2,501 UK adults reported that " $25 \%$ showed a degree of endorsement, $15 \%$ showed a consistent pattern of endorsement, and $10 \%$ had very high levels of endorsement" (Freeman et al., 2020, p.1) but a study using the same questions with a different sample and response format reported much lower levels of endorsement (Sutton \& Douglas, 2020).

The lack of knowledge about lay understandings is of particular concern since a somewhat uncritical realist perspective is currently dominant in public discourse about -- and research into -- conspiracy theories. This assumes that conspiracy beliefs are false and harmful, held only by a minority with their plausibility best judged according to the conventional criteria for evaluating scientific theories. They are also assumed to be homogenous and a priori assumptions are made about their plausibility, reflected in the kinds of beliefs selected as conspiracy theories. Yet, as we will discuss further below, there are competing scholarly perspectives on the nature of conspiracy beliefs (i.e. their definition and meaning) and on how their plausibility might be judged and it is unclear whether lay people utilize the kinds of criteria assumed by researchers in judging their plausibility.

Since it is important to make as few a priori assumptions as possible we adopt the theoretical framework of social constructionism and Q-methodology. Although Qmethodology can be used from different epistemological standpoints, Stainton Rogers and Dyson (2012) argue that, utilized from a social constructionist perspective, it can "be used to map out the terrain of possible/culturally available viewpoints on a topic" (2012, p.199) and can explore "the complex interplays among and between the discourses occupying the various niches within a discursive eco-system" (2012, p.200). Rather than take a "top-down" expert-driven approach to the definition of conspiratorial belief, we adopt a more "bottom-up" perspective, by examining lay perspectives. We report the results of two Q-methodology studies of ordinary people in the UK aiming to elucidate: what they identify as the defining 
features of conspiracy beliefs; and what aspects they consider important in judging their plausibility.

In order to locate our study in the context of the literature, we will briefly review a range of research perspectives. Firstly, we will discuss how conspiracy beliefs have been defined. Secondly, we will discuss views of how their plausibility might be judged.

\section{Competing Scholarly Perspectives on the Defining Features of Conspiratorial Belief}

Three broad, though overlapping, perspectives on the defining features of conspiracy beliefs can be delineated. As we have already noted, the most dominant in psychological and political science research is a conventional realist perspective which dates back to Hofstadter's (1964) description of conspiracy thinking as reflecting a "paranoid style". Lewandowsky and colleagues (Lewandowsky et al., 2015; Lewandowsky \& Cook, 2020) identify seven traits of such thinking: a tolerance for contradictory beliefs; a nihilistic degree of skepticism about official accounts; an assumption of nefarious intent; continually questioning that "something must be wrong" with official accounts; viewing oneself as a persecuted victim; engaging in "self-sealing" thinking that renders beliefs immune to evidence; and interpreting random events as part of a conspiracy. Hofstadter (1964) saw conspiracy theories as primarily propounded by political minorities on the right of American politics and, more recently, Uscinski and Parent (2014) have suggested that conspiracy beliefs are endorsed by political "losers" seeking to generate collective political action against a perceived threat. Within this perspective, conspiracy beliefs are often seen as harmful because they can reduce institutional trust and increase prejudice (Douglas et al., 2019) and may also lead to "vaccine hesitancy" - of particular concern in the midst of the Coronavirus pandemic (Freeman et al., 2020; Hornsey et al., 2018).

A second perspective is that conspiracy beliefs can be identified by particular narrative features or tropes and this is a more common approach in cultural and literary studies (Butter \& Knight, 2019), some psychological work (Byford, 2011) and information science (Samory \& Mitra, 2018). The focus in this perspective is less on doxastic aspects of conspiracy beliefs but, rather, their narrative form (e.g. the presence of identified conspirators and secret plots) and they may be viewed as more widespread in society, endorsed by more people and with a range of functions, including entertainment (e.g. TV series like The $X$-Files). However, some have argued that many conspiracy beliefs do not involve identifiable plots and conspirators but rather "counter conventional narratives with suspicions and allegations" (Dean, 2000). A recent variant of this broader skeptical narrative has been the "new conspiracism" (Muirhead \& Rosenblum, 2019) characterized by insinuation, assertion, delegitimation and destabilization.

A third perspective, found within the sociological and cultural studies literature, adopts a similar definition to that of the second perspective. However, within this tradition there is much more of a thoroughgoing attempt to understand their meaning in a nonpathologizing manner (Butter \& Knight, 2019). Conspiracy beliefs may be seen as meaningful attempts to understand opaque and abstract historical forces (Grewal, 2016), reflecting broader cultural anxieties and institutional distrust (Dean, 2000). They may be viewed as a popular form of knowledge, circulating outside of official channels (Birchall, 2006), moving from the fringes of culture to the mainstream (Barkun, 2003). Indeed, those endorsing such beliefs may view themselves as "critical free thinkers", engaging in social and political critique (Harambam, 2020). Within this perspective, theories are seen as forms of "stigmatized knowledge" (Barkun, 2003), unwanted by experts and elites (Bratich, 2008). These scholars emphasize that definitions of "conspiracy theories" are often ideological in nature with reference, for example, to Hofstadter's political centrism (Butter \& Knight, 2019). They often argue that the terms "conspiracy theory" and "conspiracy theorist" may serve to delegitimize accounts (e.g. Harambam, 2020). 


\section{Competing Scholarly Perspectives on Evaluating the Plausibility of Beliefs}

There are a range of different criteria by which the plausibility of conspiracy beliefs might be evaluated (Pauly, 2020) but, here, we will focus on two broad but again, overlapping, perspectives: conventional realist criteria for evaluating theories and their evidence; and heuristics concerning the motives and credibility of those making claims.

The first perspective treats conspiratorial belief claims like scientific theories, using conventional realist criteria from the philosophy of science (Pauly, 2020). Thus, a warranted conspiracy belief would be the best and most parsimonious explanation of the observed evidence, without strong contradicting evidence (Pauly, 2020). However, it has proven difficult to formulate criteria which would differentiate between warranted and unwarranted conspiracy theories (Keeley, 1999; Pauly, 2020). There have been two groupings which have developed in response: the "generalists" and the "particularists" (Pauly, 2020).

Generalists are those who presume that conspiracy beliefs are implausible in general. They argue that, although conspiracies do occur, they are rare and likely to be exposed or to fail given the difficulties in organizing them and keeping people quiet especially if they involve large numbers of people over long periods of time (Douglas et al., 2019). Thus, Levy (2007, p.181) suggests that "it is almost never rational to accept such a conspiracy theory". The generalist viewpoint is dominant in psychological and political science research (e.g. Douglas et al., 2019). Proponents suggest that, since the reasoning process underlying conspiracy beliefs is flawed, skepticism is warranted where belief claims exhibit characteristic features of conspiracy thinking (e.g. Lewandosky et al., 2015; Lewandowsy \& Cook, 2020).

Particularists take issue with this argument. Pigden (1993), for example, has argued that a conspiratorial explanation for historical events is sometimes appropriate. Instead, though still advocating the importance of realist criteria, scholars within this tradition (e.g. Coady, 2012; Dentith, 2018) argue that conspiratorial explanations need to be evaluated on a case-by-case basis, since conspiracies are not quite as rare as might be presumed and, indeed, may be more likely in particular contexts (e.g. crime, espionage, totalitarian societies etc.).

Although it has yet to be applied to conspiracy beliefs, research on public understandings of science, health and risk is very relevant to public perceptions of conspiracy beliefs and, we will argue, could be said to constitute a second broad perspective. These researchers posit that, since lay people lack the technical knowledge to evaluate scientific knowledge claims, they rely, instead, on a range of heuristics. Common heuristics include making assessments of a purported authority's expertise (Cummings, 2014) and their competence, care, fairness, and openness (Poortinga \& Pidgeon, 2003). However, public skepticism can be affected by perceptions of credibility, reliability, and integrity (Poortinga \& Pidgeon, 2003), perceptions that information is biased or distorted (Frewer et al., 1996) and concerns about the motives both of experts and informal sources of knowledge (Larson et al., 2018). Although higher levels of scientific consensus may lead to increased public perceptions of certainty about scientific knowledge this may be moderated if a person's overall trust in science is low (Chinn et al., 2018). Moreover, people may attend more to information about a source's perceived expertise and benevolence when evaluating conflicting scientific claims (Thomm \& Bromme, 2016). Concerns about bias and the influence of vested interests in science are key concerns of conspiracy beliefs and believers (Harambam, 2020) and may, therefore, resonate with broader public skepticism.

A range of research perspectives are thus available both about how we might define conspiratorial beliefs and how we might judge their plausibility. Our aim in this study is to elucidate lay perspectives on these two topics since we do not know how research 
perspectives relate to public perceptions. Indeed, there may be lay perspectives not currently addressed by researchers. As this is the first study of conspiracy belief using Qmethodology, a subsidiary aim was to test the feasibility of the design so that, in the future, it might be used with groups with a range of different perspectives on conspiracy beliefs.

\section{Method}

\section{Design}

Although Q-methodology can be used with individuals in a similar manner to repertory grids it is generally used with multiple participants when conducted from a social constructionist viewpoint (Stainton Rogers \& Dyson, 2012; Watts \& Stenner, 2012). In a Qmethodology study each participant takes individual statements from the Q-Set (the overall list of statements) and places them in a pattern (the Q-Sort). Factor analytic statistical techniques are then used but, whereas, in traditional factor analysis where the factors represent clusters of correlated statements, in Q-factor analysis, the factors are clusters of participants who have rated and sorted statements about the topic in similar ways. From a Foucauldian point of view each participant's Q-Sort represents their subject position whilst the factors can be seen as representing discourses (Watts \& Stenner, 2012). However, it is not assumed that each participant would always sort in the same way nor that participants only draw on one discourse -- a person might draw on different discursive resources depending on the interactional context. The factors indicate what discursive resources are available to participants (i.e. the range of perspectives available about a topic) and might be hypothesized to have more stability over time whereas individuals could potentially sort in different ways over time (with some people's sorts being more consistent over time than others). We return to the relationship between individuals and the factors in the discussion.

The study utilized two Q-Sets: Q-Set 1 focused on defining features of conspiracy beliefs whilst Q-Set 2 focused on what aspects of conspiracy beliefs might make them seem more, or less, plausible. The study received ethical approval from the university's institutional review board.

\section{Procedure}

\section{Developing the Q-Sets}

Watts and Stenner (2005, p.75) argue that Q-sets "can be elicited from any number of sources," with the goal of being "'broadly representative' of the relevant opinion domain, and this aim might clearly be satisfied in a number of different ways." They state that the key criteria for Q-Sets are coverage and balance. As recommended by Watts and Stenner (2005), we elicited statements from publications from a range of research perspectives (i.e. those reviewed in the introduction) identified in a narrative review process using broad search terms like "conspiracy theory" and "conspiracy belief". Items were also derived from scales measuring conspiracy beliefs and Samory and Mitra's (2018) comprehensive textual analysis of discussions in reddit conspiracy forums. Popular and social media were also sampled by using terms like "conspiracies" and "conspiracy theory" to search for relevant discussions in blogs, internet forums, websites and youtube videos.

We sought informal feedback from 14 lay people (eight women and six men with an average age of 48.3 from a range of occupations and ethnic backgrounds) who were acquaintances of the first author. Feedback was sought in three waves: four people (first wave); five people (second wave); and another five people (third wave). In the first wave of feedback, four lay people were informally interviewed about how they would define and judge the plausibility of conspiracy beliefs. Watts and Stenner (2005, p.75) suggest that statement lists can be drawn from, or supplemented by, "formal interviews" and "informal 
discussions". Interviewees are not required to be subject matter experts and can include, as we did here, potential participants. We sought to identify if there were any major gaps in our coverage of the concourse.

Watts and Stenner (2012) suggest the use of pragmatic categories to check coverage. The initial version of Q-Set 1 had 73 statements organised under the following categories of defining descriptive features of conspiracy beliefs and believers: thematic content; narrative form; identified conspirators; aspects of reasoning; the credibility of information sources; features of believers; and the consequences of beliefs. Q-Set 2 had 63 statements and the categories related to how the plausibility of conspiracy theories might be judged: aspects of the belief; aspects of reasoning; evidential basis; the extent of social support for beliefs; and aspects of conspiracy believers. A list with too many statements from one category can render a Q-Set unbalanced, whilst an overly inclusive list can make the sorting task long and demanding and so item lists need to be refined. For example, instead of an exhaustive list of all the potential harms of conspiracy beliefs we sought to ensure representation of higher order categories (e.g. "negative consequences" and "mistrust in society"). So that the Q-sets were not perceived to be biased we used descriptive terminology and sought to avoid implicit value judgements. Thus, we referred to "conspiracy beliefs" and "conspiracy believers" rather than more pejorative terms like "conspiracy theory" or "conspiracy theorist".

Stainton-Rogers and Dyson (2012, p.202) suggest that informal feedback should be sought "on whether there is a numerical balance between statements likely to be agreed or disagreed with, whether they are easy to understand and whether any items are duplicated or omitted". Thus, our second wave of feedback involved asking a further five lay people to apply these criteria to the 73 statements in Q-Set 1 and the 63 statements in Q-Set 2. In addition, the authors also used the criteria to refine the lists and rephrase statements (e.g. for clarity and balance) resulting in a final list of 34 statements for Q-Set 1 and 37 statements for Q-Set 2.

In our third wave of feedback, a further five lay people were asked to complete the online Q-Sort procedure with the final Q-Sets. They reported no problems and so no changes were made to the procedure.

\section{Gathering Q-Sort data}

The study was conducted online in 2019 using Q-sortware (http://www.qsortware.net/). In Q-methodology statements are sorted into a forced-choice quasi-normal frequency distribution. For each Q-Set, participants sorted each statement into one of nine columns expressing their level of agreement with it ranging from "strongly disagree" $(-4)$ to neutral $(0)$ to "strongly agree" $(+4)$. Figure 1 shows the distribution of the 34 cells for Q-Sort 1. As Q-Set 2 included three more statements than Q-Set 1, each of the -1, 0 and +1 columns had an extra cell

\section{FIGURE 1 ABOUT HERE}

For Q-Set 1, participants were asked to sort according to whether the feature referred to in the statement was important in defining a conspiracy theory. Thus, if they strongly agreed with a statement it would be placed in the furthest right-hand column (+4) whilst, if they strongly disagreed with the statement, it would be placed in the furthest lefthand column. For Q-Set 2, statements about aspects which participants thought made a conspiracy belief less plausible were placed in the left-hand columns with -4 indicating the least plausibility whilst those making a belief seem more plausible were sorted into columns on the right-hand side. For both Q-Sets the column in the middle was labelled "neutral". At 
the end of the sorting procedure the program requested that participants provide demographic data and answer open-ended questions about how they had sorted the statements

\section{Participants and Recruitment}

In Q-methodology, the sampling strategy is aimed at ensuring the recruitment of participants with different perspectives on a topic. Since correlates of conspiracy belief endorsement include a number of demographic variables, like education and age (Douglas et al., 2019), it seemed reasonable to recruit a general population sample varying across a number of demographic variables.

The study was advertised via regional UK Facebook groups which resulted in the successful recruitment of 56 participants from varied geographical regions - this sample size is within the 40-60 range recommended by Watts and Stenner (2012). There were 32 men and 24 women, and their ages ranged from 18-69 $(M=38.87, S D=14.13)$. Using UK Census categories, participants identified as white British (42), "any other white background" (5), black African (3), Indian (2), Bangladeshi (2), "white and black Caribbean" (1) and "white and black African" (1). Twenty-eight participants reported having no religious affiliation and the remaining participants identified as Christian (20), Muslim (4), "other" (2), Hindu (1) and Jewish (1). Political affiliations were reported as: Conservative (17); Labor (14); Liberal Democrat (10); Green Party (2); Independent Group (2); Plaid Cymru (2); Scottish National Party (1); and "other" (8). Forty-two participants reported they were in full or part-time work, seven were students, four were retired and two were unemployed. Seventeen participants were classified as professionals (e.g. doctor), 18 in a job that held responsibility (e.g. lecturer, local government), nine were in non-manual jobs (e.g. nurse), three were skilled manual workers and eight were in semi-skilled and unskilled jobs. Fifteen participants reported their highest qualification as a postgraduate degree, 17 an undergraduate degree, seven a diploma/vocational qualification, 11 a College or sixth form qualification, three a secondary school qualification, two left school before the age of sixteen and one reported having an "other" qualification. Although Q-methodology studies do not aim to have demographically representative samples (Watts and Stenner, 2012) it is worth noting that, whereas $42 \%$ of the UK population aged between 21-64 are graduates (Office for National Statistics, 2017), $59.6 \%$ of our sample were graduates.

\section{Q-factor Analysis}

Each Q-Sort was analyzed independently using PQMethod version 2.35 (Schmolck, 2014). For each Q-Sort, a principal component analysis was conducted, followed by a varimax rotation. Whilst some authorities advise that the number of factors to be extracted should be guided by whether eigenvalues are over 1.0 this can result in the extraction of "spurious factors" (Brown, 1980). Noting this debate, Watts and Stenner (2012) argue that, in addition to considering eigenvalues and total variance, decisions about the number of factors should also be guided by the meaning and significance of the factors in relation to the research questions. To guide the choice in the current study, the authors decided to choose to extract, for each Q-Sort, the number of factors which provided the best balance of the following criteria:

- The largest number of coherent factors (to represent the widest range of perspectives)

- Where the factors accounted for a large percentage of the variance

- Where the factors had loadings from larger numbers of participants with no factor having only one participant loading on it 
For Q-Sort 1, Brown's (1980) equation provided the best balance of the criteria resulting in a five-factor solution. For Q-Sort 2, applying Humphrey's rule less stringently provided the best balance. Humphrey's rule posits that "a factor is significant if the cross-product of its two highest loadings (ignoring the sign) exceeds twice the standard error" (Watts \& Stenner, 2012, p.107). However, Watts and Stenner (2012) argue that this rule can be applied less stringently so that the cross-products simply need to exceed the standard error. Adapting Humphrey's rule in this way resulted in a four-factor solution for Q-Sort 2. Deploying the same criteria for both $\mathrm{Q}$-Sorts would have seen lower variance in a factor solution, factors with only one participant loading, or a solution that represented a narrower range of perspectives.

\section{Results}

We report the full factor arrays for each $Q$-Sort (i.e. ratings of $+4,+3,+2,+1,0,-1,-2$, -3 , and -4). However, as is common practice in Q-methodology studies, our interpretation of the factors will focus on characterizing statements which are those with the strongest levels of agreement and disagreement (i.e. attracting ratings of $+3,+4,-3$ and -4 ). Where participants have given a negative rating (e.g. -3 or -4 ) to a negatively phrased statement we will use positive phrasing to avoid confusion. Where relevant, interpretation of factors draws on demographic data and qualitative responses to the open-ended questions and the factors have been named with short titles conveying their key defining aspects as expressed in the characterizing statements (Watts \& Stenner, 2012).

\section{TABLE 1 ABOUT HERE}

\section{Q-Sort 1: Features Seen as Defining Conspiracy Beliefs and Conspiracy Believers}

The eigenvalues of, and variance accounted by, each factor, both before and after rotation, can be seen in Table 1. After rotation, the five factors accounted for $63 \%$ of the total variance. The table also identifies the 42 participants who loaded on the factors. Table 2 shows the full factor array for Q-Set 1 (i.e. ratings for the statements). In the section interpreting each factor, when a particular statement is referenced the first number in parentheses is the statement number and the second is the strength of agreement or disagreement (as reported in Tables 2 and 4).

\section{TABLE 2 ABOUT HERE}

\section{Factor 1: The False, Illogical and Harmful Account}

Nineteen participants loaded on this factor which accounted for $25 \%$ of the variance. This account appeared to represent a conventional realist view. Conspiracy beliefs were seen as illogical and irrational $(6 ;-4)$, based on innuendo and suspicion rather than facts $(31 ;-4)$ and where conclusions had been reached which were not supported by the facts $(14 ;+3)$. Conspiracy believers were seen as interpreting facts to fit their predetermined theory $(30 ;+4)$, unwilling to change their belief when presented with evidence which challenged it $(34 ;-3)$ and assuming there was only one explanation for an event rather than a number of equally plausible explanations $(27 ;+3)$. One participant reported that "while scoring the statements I was thinking about specific people I know to be conspiracy believers and their unwillingness to listen to alternative explanations for the 'evidence' they have". Other highly ranked statements related to common tropes of conspiracy beliefs and believers, for example that conspiracy believers think that there are hidden connections or patterns behind world events $(28 ;-3)$, that important information is not shared with the public $(10 ;-3)$ and believing they are the only ones who understand "what is really going on" (18; +3 ). Participants also strongly agreed that conspiracy beliefs could have serious negative consequences, such as parents not vaccinating their children $(22 ;+4)$ - this was rated highly 
only on this factor and Factor 3 . This was the only factor where statements relating to the thematic content of beliefs and alleged conspirators were not rated highly.

\section{Factor 2: The Political Critique Account}

Eleven participants loaded on this factor which accounted for $15 \%$ of the variance. This account appeared to emphasize that conspiracy beliefs might be attempts to expose the truth about the powerful. In this factor, narrative tropes like information being hidden (10, $-4)$ and seeing hidden connections between world events $(28,-4)$ were noted but so also were alleged conspirators, who were seen as powerful elites $(11 ;+4)$, governments and officials $(12 ;+3)$ and intelligence agencies $(21 ;-3)$. Common characterizations of conspiracy believers as spending a lot of time reading about conspiracies on the internet $(1 ;+3)$ and believing that there was an intentional plan behind world events $(17 ;-3)$ were also seen as important. Participants loading on this factor were less critical of conspiracy beliefs and their effects and appeared to adopt a more skeptical attitude to the media. For example, they viewed conspiracy believers as thinking that the media did not routinely expose conspiracy theories $(8 ;-3)$ - this was the only factor where this statement was ranked highly. They saw conspiracy believers as crucial in exposing real-life conspiracies $(7 ;+4)$ and agreed that people used the term "conspiracy theorist" as a way of undermining a view they disagreed with $(26 ;+3)$ - these statements were highly rated in the opposite direction in two other factors. Participant 7 stated that "some world leaders hide the truth and treat people like idiots by feeding them lies" whilst Participant 23 reported that conspiracy believers preferred the term "truth seeker, or agenda researcher". More men (9) than women (2) loaded on this factor and, with an average age of 34, they were slightly younger than the overall sample. All except one were in full-time employment and only one reported a religious affiliation. None identified as Conservative and they were mainly from the center or left of politics (3 Liberal Democrat, 3 Green, 2 Labor and three who identified with other smaller parties).

\section{Factor 3: The Varied Types Account}

Four participants loaded on this factor which accounted for $7 \%$ of the variance. Its apparently contradictory sorting patterns suggests, at first glance, that it lacks coherence. For example, conspiracy beliefs were seen both as having potentially serious consequences $(22 ;+4)$ and as fun and entertaining $(3 ;+4)$. However, our interpretation is that participants loading on this factor held in mind a wide range of conspiracy beliefs with diverse effects when sorting. Thus, some beliefs might be harmful, others might be entertaining. Not all conspiracy beliefs might involve conspirators acting in secret $(2 ;-4)$ though some might involve information being hidden from the public $(10 ;-3)$. Religious groups were the only highly rated alleged conspirators $(13 ;-3)$ and it may, therefore, be significant that three of the participants loading on this factor identified with a religious faith.

\section{Factor 4: The Entertaining but Ineffectual Account}

Six participants loaded on this factor which accounted for $10 \%$ of the variance. This account appeared to focus predominantly on conspiracy beliefs which concerned powerful elites $(11 ;+3)$ but which were ineffective in preventing them from gaining too much power $(33 ;-3)$, were held by a lot of people $(23 ;+3)$ and were seen as entertaining $(3 ;+4)$ whilst two of the statements concerning potential negative consequences (22 and 29) were given ratings of zero. The factor emphasized common conspiracy tropes like believing that there was an intentional plan behind world events $(17 ;-4)$ and that there were hidden connections or patterns behind world events $(28 ;-3)$ with conspiracy believers spending a lot of time on the internet $(1 ;+3)$. 


\section{Factor 5: The Self-reinforcing Minority Account}

Only two participants loaded on this factor which accounted for $6 \%$ of the variance. These two young Labor voters saw conspiracy beliefs as not commonly held $(23 ;-3)$ and not helping to expose real conspiracies $(7 ;-3)$. They focused on beliefs concerning religious groups $(13,-4)$ and corrupt politicians and officials $(20,+3)$ and emphasized the dynamics of belief: conspiracy believers were seen as interpreting facts to fit their predetermined theory $(30 ;+3)$, unwilling to change their belief when presented with evidence which challenged it $(34 ;-3)$ and reinforcing each other's ideas $(32 ;+3)$ whilst viewing those who disagreed with them as hoodwinked or deluded $(25,+4)$.

\section{TABLE 3 ABOUT HERE}

\section{Q-Sort 2: Aspects Considered Important in Judging the Plausibility of Conspiracy Beliefs}

As can be seen in Table 3, 37 participants loaded on Q-Sort 2 and, after rotation, the four factors accounted for $70 \%$ of the variance. Table 4 presents the full factor array for $Q$ Set 2.

\section{TABLE 4 ABOUT HERE}

\section{Factor 1: The Conventional Realist Account}

Seventeen participants loaded on this factor which accounted for $26 \%$ of the variance. This account appeared to represent the conventional realist view that beliefs should be based on a reasonable interpretation of persuasive information from a range of credible sources. Participants loading on this factor emphasized the importance of a basis in facts rather than opinion $(31 ;-4)$, the need for persuasive evidence $(24 ;+3)$ from several different independent sources $(13 ;+4)$ or a whistleblower with access to secret information $(19 ;+3)$ and without strong evidence contradicting the belief $(28 ;-4)$. Conspiracy beliefs were more plausible if supported by academic and scientific consensus $(1 ;+4)$ or by someone the participant saw as credible $(12 ;+3)$ - the only factor where this latter statement was highly rated. Participant 54 suggested that whether a belief was plausible was somewhat "determined from where the information originates". Other important aspects concerned the logical structure of conspiratorial arguments. Thus, conspiracy beliefs were seen as more implausible when the conclusions reached were not supported by the evidence $(27 ;-3)$, involved jumping to conclusions $(8 ;-3)$, or were incoherent and hard to follow (18; -3). However, factors relating to the credibility of conspiracy believers were not rated highly. Participants loading on this factor tended to be predominantly white British men in full-time employment.

\section{Factor 2: The Personal Judgement Account}

Five participants loaded on this factor which accounted for $14 \%$ of the variance. In common with Factor 1, participants judged the plausibility of a belief by whether there was academic and scientific consensus about it $(1 ;+3)$, no strong evidence contradicting it $(28$; 3 ) and when it did not require one to jump to conclusions (8; -4). However, in contrast with Factor 1, two of the highest rated statements were whether a belief seemed intuitively right $(34 ;+4)$ and was hypothetically possible $(3 ;+4)$. At first glance, this appears contradictory and could indicate a lack of coherence but this was the only factor where conspiracy beliefs were seen as less plausible when the evidence for and against them was seen as confusing $(5 ;-3)$ and it was one of only two factors where a conspiracy belief was seen as less plausible when experts appeared to disagree about it $(21 ;-3)$. Moreover, compared with Factor 1, participants loading on this factor placed much more emphasis on aspects which 
might affect the credibility of conspiracy believers. Thus, conspiracy beliefs were seen as less plausible if believers were indiscriminately suspicious $(6 ;-4)$ or overly emotional $(35 ;+3)$ and more plausible if believers were open-minded about alternative explanations $(26 ;+3)$. Thus participant 13 , stated "I feel that my judgement is influenced by the personality of the person who believes in the conspiracy theory, e.g., if they are introverted or social etc." whilst Participant 15 noted that they "may judge a statement as less plausible if the believer has mental health difficulties". This may suggest that, in situations of epistemic uncertainty (i.e. where there is a lack of expert consensus and the evidence is confusing), when it is not possible to make an evaluation of the plausibility of beliefs based solely on conventional realist criteria some may draw on other heuristics like a personal assessment of the inherent plausibility of a belief and of the credibility of conspiracy believers.

\section{Factor 3: The Skeptical Realist Account}

Twelve participants loaded on this factor, which accounted for $20 \%$ of the variance. Like Factors 1 and 2, participants loading on this factor saw important indicators of the plausibility of a belief as including academic and scientific consensus $(1 ;+3)$, whether it required jumping to conclusions $(8 ;-4)$ and the absence of strong evidence contradicting it $(28 ;-4)$. As with Factor 1 , a belief was seen as more plausible if it was based on fact rather than opinion $(31 ;-3)$, with persuasive evidence $(24 ;+3)$, from several different independent sources $(13 ;+4)$ including from whistleblowers with access to secret information $(19 ;+4)$. However, participants loading on this factor rated the whistleblower statement more highly than Factor 1 and, based on their qualitative comments, they appeared to adopt a more skeptical attitude to information provided by politicians and the media. Thus Participant 7 claimed that they "trust whistle-blowers who expose secret information as some world leaders and the media hide the truth and take people for idiots by feeding them lies" whilst Participant 53 suggested that "the power of the media and what they do not say has a big impact on beliefs". This account thus appeared to emphasize that some sources of information might be biased and that a skeptical attitude was therefore necessary.

Participants loading on this factor gave high ratings to aspects affecting the credibility of conspiracy believers. In common with Factors 2 and 4 they emphasized the openmindedness of the believer $(26 ;+3)$. However, whereas participants in Factor 2 saw conspiracy believers' credibility as influenced by affective factors (e.g. indiscriminate suspicion and emotionality) here credibility was seen as influenced by social and informational biases. This was the only factor where participants gave high ratings to whether conspiracy believers seemed only to talk to people who agreed with them $(20 ;-3)$ and whether they only cited evidence which supported their belief (36; -3).

\section{Factor 4: The Critical Thinking Account}

Three participants loaded on this factor, which accounted for $10 \%$ of the variance. Five statements were highly rated on at least one other factor but statements which uniquely loaded on this factor appeared to emphasize the importance of critically analyzing a belief's implicit assumptions and the reasoning process. Thus, a conspiracy belief was seen as more plausible if it did not involve making too many assumptions $(33 ;+3)$ and less plausible if the belief was supported by circular arguments $(32 ;-4)$ or appeared to be unquestioned within the believer's social group $(37 ;-4)$ and if conspiracy believers appeared to be gullible or naïve $(17 ;+3)$.

\section{Discussion}

This study elucidated a variety of perspectives about defining conspiratorial beliefs with narrative tropes attracting most consensus as defining features. In particular the statement "'conspiracy believers think that all important information is being shared with the 
public" received consistently high levels of disagreement across Factors 1-4 (the "false, illogical and harmful", "political critique", "varied types" and "entertaining but ineffectual" accounts) and a rating of -2 in Factor 5 (the "self-reinforcing minority" account) -- see Table 2. Our focus primarily on the defining descriptive features of conspiracy beliefs may have resulted in more consensus than if we had asked about their representation or meaning. However, even so, the meaning of conspiracy beliefs was not entirely absent since the "political critique" account appeared to represent an alternative perspective to the arguably more pathologizing perspective represented by Factor 1 (the "false, illogical and harmful" account). Moreover, there was variation across the factors on four key issues. Firstly, whilst conspiracy beliefs were seen as common by participants loading on Factors 3 and 4 (the "varied types" and "entertaining but ineffectual" accounts respectively), they were understood as held only by a minority of people within Factor 5 (the "self-reinforcing minority" account). This mirrors the debate between scholars like Hofstadter (1964), who saw conspiracy beliefs as held by (political) minorities, and researchers from narrative and cultural perspectives who view them as more widely held (e.g. Butter \& Knight, 2019).

Secondly, within Factor 1 (the "false, illogical and harmful" account), conspiracy beliefs were viewed as harmful, within Factor 4 (the "entertaining but ineffectual" account) they were seen as entertaining whilst, within Factor 3 (the "varied types" account), they were understood as equally harmful and entertaining. Again, this mirrors differences in the literature. Cultural studies researchers have examined the entertainment derived from conspiracy narratives in popular culture whilst psychologists and political scientists have focused more on the harms associated with conspiracy beliefs. Although Douglas et al (2019) briefly note that conspiracy beliefs might have beneficial effects for some people this topic has been much less investigated within this tradition. Thirdly, within Factor 2 (the "political critique" account), conspiracy theories were viewed as crucial in exposing real-life conspiracies, whilst those loading on Factor 5 (the "self-reinforcing minority" account) took the opposite view. To some degree, this reflects debates between generalists -- who assume that conspiracy beliefs are inherently implausible -- and particularists who adopt a more case-by-case approach (Pauly, 2020). However, some within the conventional realist perspective acknowledge that conspiracies do occur though Lewandowsky and Cook (2020) argue that they are discovered through conventional skeptical thinking and consideration of evidence and not "hyperskeptical" conspiratorial thinking. Lastly, within Factor 2 (the "political critique" account) the term "conspiracy theorist" was viewed as a way of undermining beliefs people disagreed with - an argument made by researchers from the non-pathologising approach within cultural studies (Butter \& Knight, 2019) -- whereas participants loading on Factor 4 (the "entertaining but ineffectual" account) disagreed with this. As a whole, these results suggest that conspiracy beliefs may not be universally viewed as homogenous.

A variety of perspectives was also elucidated about how the plausibility of conspiracy beliefs should be judged with the statement "when a majority of academic researchers and scientists endorse the belief" receiving consistently high ratings across the factors suggesting this may be an important heuristic for ordinary people (Chinn et al., 2018). Although all the factors included at least one conventional realist criterion, two aspects were under-emphasized in Factor 1 (the "conventional realist" account). Firstly, it did not address the issue of epistemic uncertainty whereas, in contrast, participants loading on Factors 2 and 4 (the "personal judgement" and "critical thinking" accounts respectively) considered a belief was less plausible if experts disagreed about it whilst those loading on Factor 2 also considered whether the evidence was confusing. Our interpretation suggests that a key aspect differentiating these two factors was that participants responded to epistemic uncertainty in different ways, in line with the name we gave the factors, with some emphasizing the importance of personal judgement (as in Factor 2) and others emphasizing aspects of critical thinking (as in Factor 4). Secondly, Factor 1 (the "conventional realist" account) under-emphasized statements concerning informational bias whereas, in other factors, higher ratings were given to statements relating to different kinds of bias: affective biases (Factor 2: the "personal judgement" account); passive and implicit biases (Factor 4: 
the "critical thinking" account); and more active informational biases (Factor 3: the "skeptical realist" account). Participants appeared to respond to informational bias by attending to the credibility of conspiracy believers. Moreover, it is noteworthy that a conventional realist approach to plausibility appeared to be associated predominantly with white British employed men. Dominant constructions of rationality may reflect assumptions of gender and culture (Falmagne \& Hass, 2002) and the influence of this on judgements of plausibility merits further study.

From a mainstream research perspective conspiracy beliefs should, therefore, be viewed as of varied types and multi-dimensional in nature with potential dimensions including: how commonly held they are; what their effects are (e.g. how effective, harmful and entertaining they are); the extent to which they involve plots and conspirators or a more general skepticism about information being withheld; the extent to which they might function as political or social critiques of the status quo (and how effective they are in uncovering actual conspiracies); and the perceived ideological allegiance of the definition. Similarly, judgements of plausibility may also be multi-dimensional with potential candidate dimensions including: the level of expert consensus; logical and critical reasoning; the nature of the evidence; the extent of epistemic uncertainty; the credibility of conspiracy believers and proponents (e.g. how open-minded or explicitly or implicitly biased they are perceived to be); and the perceived bias of information sources. Researchers might also investigate the social and psychological correlates of different perspectives on defining and judging the plausibility of conspiracy beliefs.

A subsidiary aim of the study was to assess the feasibility of a Q-methodology approach to conspiracy beliefs. In general, the study design appears feasible for future use: the procedures worked well and the statements used in the Q-Sets appeared to be acceptable to participants. However, some participants found the online Q-sortware program not very user-friendly in some respects and so alternative online platforms (e.g. Qualtrics) could be considered. We suggest that future Q-methodology studies should be conducted with groups likely to have very different perspectives on conspiracy beliefs (e.g. members of particular conspiracy belief communities, climate scientists etc.) to see if similar or different perspectives are elucidated. They could also examine different types of research questions. For example, as we saw in the introduction, there is scholarly debate about the meaning of conspiracy beliefs and how they are represented and, of course, these would also have implications for policy responses so future Q-methodology studies could examine representations, understandings and policy responses. Such studies might generate even more varied perspectives than our focus on definitions and plausibility criteria. Qmethodology could also be used to investigate both lay and professional perspectives on other kinds of contested beliefs, for example, those attracting psychiatric labels like "delusions".

Given the correlation between education and conspiratorial belief (Douglas et al., 2019) our sample's higher levels of education might mean we did not adequately sample a range of perspectives. In addition, Q-methodology studies have a number of inherent limitations like the forced-choice sorting format. Developing Q-Sets with sufficient coverage and balance can also be a challenge. We think that we provided sufficient coverage of the concourse and none of our participants reported either that the statements seemed biased or that they were not able to represent their viewpoint. Moreover, the inclusion of openended questions so participants can explain their sorting approach also enables them to comment on other issues (e.g. some commented on the Q-Sortware program). However, it may be that studies with other groups of participants might reveal that the Q-Sets lack sufficient coverage or are unbalanced. Future Q-methodology studies in different cultural contexts could further develop these Q-Sets. 
There are inherent dangers with factor analytic studies: minority perspectives may be over-emphasized whilst naming factors might over-emphasize some aspects and present them as more internally coherent than they are. For example, some of the factors with fewer participants appeared less coherent than those with more participants. In addition, there is a danger that factors can be reified. As noted in the method section, it is not assumed that participants loading on a factor would only draw on the discursive resource exemplified by that factor. In everyday conversation, individuals respond to contextual demands and, indeed, individual participants might sort the statements differently at other times. Whether the factors have more stability could be examined by future researchers conducting studies on a range of populations. Even so, it should be borne in mind that the factors reported here arise from data gathered from a particular group of people in a particular historical and cultural context. Furthermore, it is possible that other researchers might interpret the factors differently. As a result, we have sought to be transparent by clearly stating our criteria for selecting factor solutions and by including the full factor arrays, enabling others to develop alternative interpretations.

The extent to which these limitations have posed a problem will only be clarified by Q-methodology studies on conspiracy beliefs with other populations. In addition, with notable exceptions like Harambam (2020), there has been much less qualitative research on conspiratorial belief than quantitative research yet surveys of conspiracy beliefs can be hard to interpret as the debate between Freeman et al (2020) and Sutton and Douglas (2020) about the extent of Coronavirus conspiracy beliefs in the UK demonstrates. Further ethnographic and discourse analytic research might give more insight into the ways in which lay people draw on different discursive resources in different interactional contexts when discussing and evaluating conspiracy beliefs.

A social constructionist perspective need not lead to moral relativism - the existence of multiple understandings does not mean all are equally desirable. Some conspiratorial narratives are clearly used to warrant harmful social actions like the promotion of prejudice, political polarization, denial of anthropogenic climate change and so on. However, our findings suggest that, in developing educational and policy responses to such narratives, we should consider that there may be multiple competing perspectives about them in the general population. It is possible that interventions targeted at "conspiracy theories" as if they were universally understood as homogenous may have more limited effects than those which focus on more specific types of narratives and consider how they may be understood differently by different sections of the population. Those designing interventions should clarify how target populations might understand conspiracy beliefs so that messages can can be appropriately adapted. For example, for many of our participants, interventions with an implicit or explicit assumption that conspiracies never take place or that epistemic certainty is always achievable might be less effective than more nuanced approaches. Furthermore, educational interventions which focus only on the development of scientific reasoning are likely to be insufficient as these were not the only criteria highly rated by our participants. Instead, heuristics like assessing the credibility of authorities could be fostered, since these may be more useful in situations of epistemic uncertainty.

Given the skepticism towards the media seen in both the "political critique" and "skeptical realist" accounts, interventions might focus on developing "news media literacy" which refers to the ability to identify informational bias by learning about how media content is produced and distributed, the influence of corporate ownership on these processes and thus to discern what information is trustworthy (Craft et al., 2017). However, in addition, interventions could also focus more on understanding the reasons why certain harmful narratives gain traction since they often point to broader problems in societies. 


\section{References}

Barkun, M. (2003). A culture of conspiracy: Apocalyptic visions in contemporary America. University of California Press.

Birchall, C. (2006) Knowledge goes pop: From conspiracy theory to gossip. Berg.

Bratich, J.Z. (2008). Conspiracy panics: Political rationality and popular culture. State of New York University Press.

Brown, S. R. (1980). Political subjectivity. Yale University Press.

Butter, M. \& Knight, P. (2019). The history of conspiracy theory research: A review and commentary. In J.E. Uscinski (Ed.), Conspiracy theories and the people who believe them (pp.33-46). Oxford University Press.

Byford, J. (2011). Conspiracy theories: A critical introduction. Palgrave MacMillan.

Chinn, S., Lane, D. S., \& Hart, P. S. (2018). In consensus we trust? Persuasive effects of scientific consensus communication. Public Understanding of Science, 27(7), 807823. https://doi.org/10.1177\%2F0963662518791094

Coady, D. (2012). What to believe now: Applying epistemology to contemporary issues. Wiley.

Craft, S., Ashley, S., \& Maksl, A. (2017). News media literacy and conspiracy theory endorsement. Communication and the Public, 2(4), 388-401. https://doi.org/10.1177/2057047317725539

Cummings, L. (2014). The "trust" heuristic: Arguments from authority in public health. Health Communication, 29(10), 1043-1056. https://doi.org/10.1080/10410236.2013.831685

Dean, J. (2000). Theorizing conspiracy theory. Theory \& Event 4(3). https://www.muse.jhu.edu/article/32599

Dentith, M. (2018). Taking conspiracy theories seriously. Rowman \& Littlefield.

Douglas, K.M., Uscinski, J.E., Sutton, R.M., Cichocka, A., Nefes, T., Ang, C.S. \& and Deravi, F. (2019). Understanding conspiracy theories. Political Psychology, 40(S1:

Advances in Political Psychology): 3-35. https://doi.org/10.1111/pops.12568

Falmagne, R. J., \& Hass, M. (2002). Representing reason: Feminist theory and formal logic. Rowman \& Littlefield.

Freeman, D., Waite, F., Rosebrock, L., Petit, A., Causier, C., East, A., Jenner, L., Teale, A, Carr, L., Mulhall, S., Bold, E. \& Lambe, S. (2020). Coronavirus conspiracy beliefs, mistrust, and compliance with government guidelines in England. Psychological Medicine, 1-30. https://doi.org/10.1017/S0033291720001890

Frewer, L. J., Howard, C., Hedderley, D., \& Shepherd, R. (1996). What determines trust in information about food-related risks? Underlying psychological constructs. Risk Analysis, 16(4), 473-486. https://doi.org/10.1111/j.1539-6924.1996.tb01094.x

Grewal, D. (2016). Conspiracy theories in a networked world. Critical Review, 28(1), 24-43. https://doi.org/10.1080/08913811.2016.1167404

Guilhot, N. \& Moyn, S. (2020, 13 February). The Trump era is a golden age of conspiracy theories - on the right and left. The Guardian.

https://www.theguardian.com/commentisfree/2020/feb/13/trump-era-conspiracytheories-left-right

Harambam, J. (2020). Contemporary conspiracy culture: Truth and knowledge in an era of epistemic instability. Routledge.

Hofstadter, R. (1964). The paranoid style in American politics and other essays. Harvard University Press.

Hornsey, M. J., Harris, E. A., \& Fielding, K. S. (2018). The psychological roots of antivaccination attitudes: A 24-nation investigation. Health Psychology, 37(4), 307-315. https://doi.apa.org/doi/10.1037/hea0000586

Keeley, B. (1999). Of conspiracy theories. The Journal of Philosophy, 96(3), 109-126. https://doi.org/10.2139/ssrn.1084585

Larson, H. J., Clarke, R. M., Jarrett, C., Eckersberger, E., Levine, Z., Schulz, W. S., \& Paterson, P. (2018). Measuring trust in vaccination: A systematic review. Human 
Vaccines \& Immunotherapeutics, 14(7), 1599-1609.

https://doi.org/10.1080/21645515.2018.1459252

Levy, N. (2007). Radically socialized knowledge and conspiracy theories. Episteme, 4(2), 181-192. https://doi.org/10.3366/epi.2007.4.2.181

Lewandowsky, S., \& Cook, J. (2020). The conspiracy theory handbook. http://sks.to/conspiracy

Lewandowsky, S., Cook, J., Oberauer, K., Brophy, S., Lloyd, E. A., \& Marriott, M. (2015). Recurrent fury: Conspiratorial discourse in the blogosphere triggered by research on the role of conspiracist ideation in climate denial. Journal of Social and Political Psychology, 3(1), 142-178. https://doi.org/10.5964/jspp.v3i1.443

Muirhead, R. \& Rosenblum, N. (2019). A lot of people are saying: The new conspiracism and the assault on democracy. Princeton University Press.

Office for National Statistics (2017, 24 November). Graduates in the UK Labor market: 2017.

https://www.ons.gov.uk/employmentandLabormarket/peopleinwork/employmentande mployeetypes/articles/graduatesintheukLabormarket/2017

Pauly, M. (2020). Conspiracy theories. In J. Fieser, \& B. Dowden (Eds.), The Internet Encyclopedia of Philosophy. https://www.iep.utm.edu/conspira/

Pigden, C. (1995). Popper revisited, or what is wrong with conspiracy theories? Philosophy of the Social Sciences, 25(1), 3-34. https://doi.org/10.1177/004839319502500101

Poortinga, W., \& Pidgeon, N. F. (2003). Exploring the dimensionality of trust in risk regulation. Risk Analysis: An International Journal, 23(5), 961-972. https://doi.org/10.1111/1539-6924.00373

Samory, M., \& Mitra, T. (2018). "The government spies using our webcams:" the language of conspiracy theories in online discussions. Proceedings of the ACM on HumanComputer Interaction, 2(CSCW), 152. https://doi.org/10.1145/3274421

Schmolck, P. (2014). PQMethod (version 2.35) [computer software]. http://schmolck.org/qmethod/

Stainton Rogers, W., \& Dyson, P. O. (2012). Q methodological research in mental health and psychotherapy. In D. Harper \& A. Thompson (eds) Qualitative research methods in mental health and psychotherapy: An introduction for students and practitioners (pp.193-208). Wiley.

Sutton, R.M. \& Douglas, K.M. (2020). Agreeing to disagree: Reports of the popularity of Covid-19 conspiracy theories are greatly exaggerated. Psychological Medicine, 1-3. https://doi.org/10.1017/S0033291720002780

Thomm, E., \& Bromme, R. (2016). How source information shapes lay interpretations of science conflicts: Interplay between sourcing, conflict explanation, source evaluation, and claim evaluation. Reading and Writing, 29(8), 1629-1652. https://doi.org/10.1007/s11145-016-9638-8

Uscinski, J. E., \& Parent, J. M. (2014). American conspiracy theories. Oxford University Press.

Watts, S. \& Stenner, P. (2005). Doing Q methodology: theory, method and interpretation. Qualitative Research in Psychology, 2(1), 67-91. https://doi.org/10.1191/1478088705qp022oa

Watts, S., \& Stenner, P. (2012). Doing Q methodological research: Theory, method \& interpretation. Sage. 
Figure 1: Visual depiction of the forced quasi-normal distribution in Q-Sort 1

\begin{tabular}{l}
$\begin{array}{l}\text { Strongly } \\
\text { Disagree }\end{array}$ \\
\hline-4 \\
\hline
\end{tabular}


Table 1: Eigenvalues for and percentage of variance accounted by each factor

\begin{tabular}{lllll}
\hline Factor & Eigenvalue & $\begin{array}{l}\text { \% variance } \\
\text { before rotation }\end{array}$ & $\begin{array}{l}\% \text { variance } \\
\text { after rotation }\end{array}$ & $\begin{array}{l}\text { Number of Sorts (i.e. } \\
\text { participants) loading }\end{array}$ \\
\hline 1 & 20.82 & 37 & 25 & $\begin{array}{l}1,2,10,14,15,19,24,25, \\
27,30,32,34,37,38,48, \\
\end{array}$ \\
& & & & $49,50,53,56$ \\
2 & 5.41 & 10 & 15 & $\begin{array}{l}5,7,12,13,17,18,23,40, \\
\end{array}$ \\
3 & 3.37 & 6 & $75,46,47$ \\
4 & 3.01 & 5 & 10 & $4,6,44,55$ \\
5 & 2.57 & 5 & 6 & $11,16,22,26,42,51$ \\
\hline
\end{tabular}


Table 2: Full factor array for Q-Set 1 (defining features of conspiracy beliefs)

\begin{tabular}{|c|c|c|c|c|c|c|}
\hline & & Factor 1 & Factor 2 & Factor 3 & Factor 4 & Factor 5 \\
\hline 1 & $\begin{array}{l}\text { Conspiracy believers spend a lot of time reading about conspiracies on } \\
\text { the internet }\end{array}$ & +1 & +3 & +3 & +3 & +1 \\
\hline 2 & Conspiracy beliefs assume that conspirators act in secret & +1 & +2 & -4 & +4 & 0 \\
\hline 3 & Conspiracy beliefs can be fun and entertaining & -2 & 0 & +4 & +4 & +2 \\
\hline 4 & People enjoy talking to conspiracy believers & -1 & -1 & +3 & +2 & -2 \\
\hline 5 & $\begin{array}{l}\text { Conspiracy beliefs assume that events are caused by large groups of } \\
\text { conspirators acting independently }\end{array}$ & -1 & -2 & -2 & 0 & -1 \\
\hline 6 & Conspiracy beliefs are logical and rational & -4 & 0 & -2 & +1 & -2 \\
\hline 7 & $\begin{array}{l}\text { Conspiracy believers are crucial in exposing real-life conspiracies (e.g. } \\
\text { Watergate) }\end{array}$ & 0 & +4 & -1 & -1 & -3 \\
\hline 8 & $\begin{array}{l}\text { Conspiracy believers think that the media routinely expose conspiracy } \\
\text { theories }\end{array}$ & -1 & -3 & 0 & 0 & -1 \\
\hline 9 & Conspiracy believers distrust academic researchers and scientists & +2 & 0 & 0 & 0 & +2 \\
\hline 10 & $\begin{array}{l}\text { Conspiracy believers think that all important information is being } \\
\text { shared with the public }\end{array}$ & -3 & -4 & -3 & -4 & -2 \\
\hline 11 & The conspirators in conspiracy beliefs are often powerful elites & 0 & +4 & 0 & +3 & 0 \\
\hline
\end{tabular}




\begin{tabular}{|c|c|c|c|c|c|c|}
\hline 12 & $\begin{array}{l}\text { The conspirators in conspiracy beliefs are often governments or } \\
\text { officials }\end{array}$ & 0 & +3 & +1 & +2 & +1 \\
\hline 13 & $\begin{array}{l}\text { The conspirators in conspiracy beliefs rarely involve people from } \\
\text { religious groups (e.g. Jews, Muslims etc.) }\end{array}$ & -2 & -2 & -3 & -2 & -4 \\
\hline 14 & $\begin{array}{l}\text { Conspiracy beliefs take accepted facts but then make a big leap of faith } \\
\text { to reach conclusions that aren't supported by the facts }\end{array}$ & +3 & -2 & -4 & +1 & 0 \\
\hline 15 & $\begin{array}{l}\text { Conspiracy believers think events happen because of the planned } \\
\text { actions of small groups, rather than broader forces like economic or } \\
\text { political systems }\end{array}$ & +1 & +1 & -2 & -1 & +3 \\
\hline 16 & $\begin{array}{l}\text { Conspiracy beliefs assume that conspirators manipulate events to } \\
\text { serve their own interests }\end{array}$ & +2 & +2 & -1 & +2 & -2 \\
\hline 17 & $\begin{array}{l}\text { Conspiracy believers do not believe that there is an intentional plan } \\
\text { behind world events }\end{array}$ & -2 & -3 & -1 & -4 & -2 \\
\hline 18 & $\begin{array}{l}\text { Conspiracy believers believe that they are the only ones who } \\
\text { understand 'what is really going on' }\end{array}$ & +3 & +1 & +1 & +1 & +2 \\
\hline 19 & $\begin{array}{l}\text { Conspiracy beliefs are so complex that it can be hard to definitively } \\
\text { disprove them }\end{array}$ & +1 & 0 & 0 & -1 & -4 \\
\hline 20 & Conspiracy believers think that all politicians and officials are corrupt & -1 & 0 & -2 & -1 & +3 \\
\hline 21 & $\begin{array}{l}\text { The conspirators in conspiracy beliefs do not typically involve } \\
\text { intelligence agencies }\end{array}$ & -1 & -3 & -1 & -2 & +2 \\
\hline 22 & $\begin{array}{l}\text { Conspiracy beliefs can have serious negative consequences, such as } \\
\text { parents not vaccinating their children }\end{array}$ & +4 & +1 & +4 & 0 & +1 \\
\hline 23 & A lot of people believe in conspiracies & 0 & -1 & +3 & +3 & -3 \\
\hline
\end{tabular}




\begin{tabular}{|c|c|c|c|c|c|c|}
\hline 24 & Conspiracy beliefs lead to some groups of society being treated badly & 0 & +1 & +2 & 0 & 0 \\
\hline 25 & $\begin{array}{l}\text { Conspiracy believers see those who disagree with them as } \\
\text { hoodwinked or deluded }\end{array}$ & +2 & +2 & +1 & +1 & +4 \\
\hline 26 & $\begin{array}{l}\text { People use the term 'conspiracy theorist' as a way of undermining a } \\
\text { view they disagree with }\end{array}$ & 0 & +3 & +2 & -3 & -1 \\
\hline 27 & $\begin{array}{l}\text { Conspiracy believers assume that there is only one explanation for an } \\
\text { event when, in fact, there are a number of equally plausible } \\
\text { explanations }\end{array}$ & +3 & -1 & +1 & 0 & +1 \\
\hline 28 & $\begin{array}{l}\text { Conspiracy believers think that there are no hidden connections or } \\
\text { patterns behind world events }\end{array}$ & -3 & -4 & 0 & -3 & -1 \\
\hline 29 & $\begin{array}{l}\text { Conspiracy beliefs have caused a destructive level of mistrust in } \\
\text { society }\end{array}$ & +1 & 0 & +1 & -2 & +1 \\
\hline 30 & Conspiracy believers interpret facts to fit their predetermined theory & +4 & -1 & +2 & +2 & +3 \\
\hline 31 & $\begin{array}{l}\text { Conspiracy beliefs are based on evidence, rather than innuendo and } \\
\text { suspicion }\end{array}$ & -4 & +1 & -3 & -1 & -1 \\
\hline 32 & Conspiracy believers reinforce each other's ideas & +2 & +2 & +2 & +1 & +3 \\
\hline 33 & Conspiracy beliefs prevent elites from gaining too much power & -2 & -2 & -1 & -3 & 0 \\
\hline 34 & $\begin{array}{l}\text { Conspiracy believers are happy to change their belief when they are } \\
\text { presented with evidence which challenges it }\end{array}$ & -3 & -1 & 0 & -2 & -3 \\
\hline
\end{tabular}


Table 3: Eigenvalues and total variance for the four extracted factors

\begin{tabular}{lllll}
\hline Factor & Eigenvalue & $\begin{array}{l}\text { \% variance } \\
\text { before rotation }\end{array}$ & $\begin{array}{l}\% \text { variance after } \\
\text { rotation }\end{array}$ & $\begin{array}{l}\text { Number of sorts (Ps) } \\
\text { loading }\end{array}$ \\
\hline 1 & 33.1943 & 58.24 & 26 & $1,8,9,11,17,22,23$, \\
& & & $\begin{array}{l}31,36,38,39,41,47, \\
48,50,54,55\end{array}$ \\
2 & 2.5487 & 4.47 & 14 & $5,13,15,29,37$ \\
3 & 2.1273 & 3.73 & 20 & $\begin{array}{l}7,10,12,16,18,20,24, \\
\end{array}$ \\
& & & & $40,44,46,53,56$ \\
\hline
\end{tabular}


Table 4: Full factor array for Q-Set 2 (aspects considered important in judging the plausibility of a conspiracy belief)

\begin{tabular}{|c|c|c|c|c|c|}
\hline & & Factor 1 & Factor 2 & Factor 3 & Factor 4 \\
\hline 1 & When a majority of academic researchers and scientists endorse the belief & +4 & +3 & +3 & +4 \\
\hline 2 & When the believer is very sociable and has lots of friends & 0 & 0 & -1 & -1 \\
\hline 3 & When the belief appears to be hypothetically possible & +2 & +4 & +1 & +1 \\
\hline 4 & When the believer is highly educated & +2 & +2 & 0 & 0 \\
\hline 5 & When the evidence for and against the belief is confusing & -1 & -3 & -1 & +1 \\
\hline 6 & When the believer seems indiscriminately suspicious & -2 & -4 & -2 & -1 \\
\hline 7 & $\begin{array}{l}\text { When the believer is from a different social group (cultural, ethnic, religious, political } \\
\text { etc.) to you }\end{array}$ & 0 & 0 & -1 & -1 \\
\hline 8 & $\begin{array}{l}\text { When the belief seems to involve jumping to a particular conclusion not supported } \\
\text { by the evidence }\end{array}$ & -3 & -4 & -4 & 0 \\
\hline 9 & When most people you know don't believe it & 0 & -2 & 0 & +1 \\
\hline 10 & $\begin{array}{l}\text { When the belief pins the blame for something on an identifiable group of people } \\
\text { rather than something more abstract }\end{array}$ & 0 & 0 & -1 & -2 \\
\hline 11 & When the conspiracy would have required lots of different people to co-operate & -2 & +1 & +1 & +3 \\
\hline
\end{tabular}




\begin{tabular}{|c|c|c|c|c|c|}
\hline 12 & When someone you think is credible believes it & +3 & +2 & +1 & 0 \\
\hline 13 & When the belief is based on several different independent sources of evidence & +4 & 0 & +4 & +2 \\
\hline 14 & $\begin{array}{l}\text { When the believer will change their mind in light of evidence which contradicts the } \\
\text { belief }\end{array}$ & +1 & -1 & -1 & +1 \\
\hline 15 & When the believer seems to spend a lot of time on conspiracy websites & -1 & -1 & 0 & +1 \\
\hline 16 & When official sources (e.g. government reports) do not support it & 0 & -1 & +1 & 0 \\
\hline 17 & When the believer does not seem gullible or naïve & +1 & +1 & +1 & +3 \\
\hline 18 & When the belief is presented in an incoherent and hard to follow manner & -3 & -1 & 0 & -3 \\
\hline 19 & $\begin{array}{l}\text { When the belief is supported by a whistleblower who has had access to secret } \\
\text { information }\end{array}$ & +3 & +1 & +4 & -2 \\
\hline 20 & When the believer only seems to talk to people who agree with them & -1 & -1 & -3 & -2 \\
\hline 21 & When experts seem to disagree about the belief & -1 & -3 & +1 & -3 \\
\hline 22 & When the believer is not obsessed by the belief & +1 & 0 & 0 & 0 \\
\hline 23 & When the belief seems to be the simplest explanation of the evidence & +1 & +1 & +2 & +1 \\
\hline 24 & When the believer can provide persuasive evidence for it & +3 & +2 & +3 & +2 \\
\hline 25 & When the believer seems eccentric or odd & -1 & -2 & -1 & 0 \\
\hline
\end{tabular}




\begin{tabular}{|c|c|c|c|c|c|}
\hline 26 & $\begin{array}{l}\text { When the believer seems to be open-minded about alternative explanations when } \\
\text { they weigh up the evidence }\end{array}$ & +2 & +3 & +3 & +4 \\
\hline 27 & When the conclusions reached seem to go beyond the evidence & -3 & -1 & +2 & -1 \\
\hline 28 & When you are aware of strong evidence which contradicts the belief & -4 & -3 & -4 & +2 \\
\hline 29 & When the belief fits with my own political views & +1 & 0 & 0 & -1 \\
\hline 30 & When the believer appears to have mental health difficulties & -1 & -2 & -2 & -1 \\
\hline 31 & When the belief seems to be based on opinion rather than fact & -4 & -2 & -3 & -3 \\
\hline 32 & When the argument for a belief seems circular & -2 & +1 & -2 & -4 \\
\hline 33 & When the belief doesn't involve making too many assumptions & +2 & +2 & +2 & +3 \\
\hline 34 & When the belief just seems intuitively right & +1 & +4 & +2 & +2 \\
\hline 35 & When the believer does not get overly emotional about the belief & 0 & +3 & 0 & 0 \\
\hline 36 & $\begin{array}{l}\text { When the believer only cites evidence which supports their belief and does not } \\
\text { mention anything which might contradict it }\end{array}$ & -2 & +1 & -3 & -2 \\
\hline 37 & When the belief seems to be unquestioned within the believer's social group & 0 & 0 & -2 & -4 \\
\hline
\end{tabular}


